\title{
MENINGKATKAN HASIL BELAJAR ALJABAR SISWA DENGAN MENGGUNAKAN METODE TUTOR SEBAYA DI SMP NEGERI 175 JAKARTA
}

\author{
ESTER EKARISTA SINAMBELA \\ Guru SMP Negeri 175 Jakarta
}

\begin{abstract}
Abstrak. Penelitian ini membahas tentang peningkatan pengetahuan siswa dalam belajar Aljabar dengan menggunakan teknik tutor sebaya. Tujuan dari penelitian ini adalah untuk menemukan apakah pengetahuan siswa mengenai Aljabar bisa meningkat apabila diajarkan dengan menggunkan teknik tutor sebaya. Penelitian dilaksanakan dalam bentuk penelitian tindakan kelas. Subjek dari penelitian ini adalah kelas VIII siswa SMP Negeri 175, dimana dari keseluruhan kelas diambil satu kelas saja yaitu kelas VIII.3, dengan jumlah 36 orang. Adapun instrument yang digunakan dalam penelitian ini adalah test mengenai Aljabar. Dalam penganalisisan data, ditemukan bahwa rata-rata niliai siswa pada test awal adalah 4.1, rata-rata pada test 1 siklus satu adalah 4.7, rata-rata pada post test siklus 1 yaitu 5.6, rata-rata test pertama siklus dua yaitu 6.6 dan rata-rata test akhir siklus 2 adalah 7.2. Dan persentasi total peningkatan dari pre-test sampai dengan post-test siklus ke dua adalah 75.6\%. Jadi dapat disimpulkan bahwa pengajaran Aljabar dengan teknik tutor sebaya dapat meningkatkan pengetahuan siswa, sehingga disarankan kepada guru untuk menggunakan teknik tutor sebaya dalam mengajarkan Aljabar.
\end{abstract}

Kata Kunci: tutor sebaya, penelitian tindakan kelas, matematika, aljabar

\begin{abstract}
This study presents a research report on improving students' Knowledge on learning Aljabar through Cross Age Tutoring. The objective was to find out whether students' knowledge improved taught by Cross Age Tutoring. It was conducted using classroom action research method. The subject of the study was the Grade VIII students of State Junior High School 175, Jakarta. One class from eight parallel classes was taken as the subject of this research namely the grade VIII.3. The numbers of the students were 36. They were taught Aljabar using Cross Age Tutoring technique. The instruments used were test. In analyzing the data, the mean of the students' score for the pre-test was 4.1, for progressing- test ${ }_{1}$ was 4.7 , for progressing-test ${ }_{2}$ (Post Test for first Cycle) was 5,6, for progressing-test $_{3}$ was 6,6 and the post-test (Second Cycle) was 7,2 and the total percentage of the improvement from the pre-test to post-test was 75,6\%. The conclusion is that the Cross Age Tutoring can improve the students' knowledge on learning algebra. It is suggested that teachers should apply Cross Age Tutoring technique as one of the strategies to improve students' knowledge on learning algebra.
\end{abstract}

Keywords: cross age tutoring, classroom action research, mathematics, algebra

\section{PENDAHULUAN}

Guru memiliki peran dan fungsi penting dalam keseluruhan proses pendidikan di sekolah, karena dalam pelaksanaan tugasnya sebagai pengajar maupun sebagai pendidik. Untuk dapat melaksanakan tugasnya dengan baik, seorang guru hendaknya memahami segala aspek pribadi anak didik dari segi jasmani maupun rohaninya. Guru hendaknya mengenal dan memahami tingkat perkembangan, sistem motivasi, pribadi, kecakapan serta kesehatan mental anak didik. Dan guru juga harus bertanggung jawab dalam menerapkan pembelajaran sampai peserta didik menguasai materi pembelajaran secara tuntas. Sehingga tidak terjadi masalah besar dalam bidang pendidikan di sekolah yang 
banyak diperbincangkan saat ini seperti; adalah rendahnya mutu pendidikan yang tercermin dari rendahnya rata-rata prestasi belajar, khususnya peserta didik Sekolah Dasar dan Sekolah Menengah Pertama. Pembelajaran yang berhasil ditunjukkan oleh dikuasainya materi pelajaran oleh siswa. Tingkat penguasaan siswa terhadap materi pelajaran yang biasanya dinyatakan dengan nilai. Dalam pembelajaran inilah sering terjadi banyak masalah yang dihadapi oleh siswa. Hal tersebut disebabkan oleh berbagai faktor baik faktor eksternal maupun faktor internal. Faktor eksternal tersebut adalah faktor yang berasal dari luar pribadi siswa sedangkan faktor internal adalah faktor yang berasal dari dalam pribadi siswa. Salah satu contoh dari fakor eksternal adalah teknik belajar yang kurang efisien dalam proses pembelajaran yang terjadi di dalam kelas. Sedangkan contoh faktor internal yang mempengaruhi hasil belajar siswa adalah minat dan motivasi dalam belajar.

Dari pengalaman yang didapatkan oleh penulis ketika sedang mengajarkan mata pelajaran Matematika mengenai Aljabar, ditemukan bahwa hasil ulangan menunjukkan rendahnya tingkat penguasaan atau prestasi belajar siswa dalam belajar Aljabar. terdapat hanya 4 orang dari 36 siswa di kelas VIII yang mencapai tingkat penggunaan materi sebesar $70 \%$ ke atas. Berbicara tentang rendahnya daya serap atau prestasi belajar, atau belum terwujudnya keterampilan proses dan pembelajaran Aljabar yang menekankan pada peran aktif peserta didik, inti persoalannya adalah pada masalah "ketuntasan belajar" yakni pencapaian taraf penguasaan minimal yang ditetapkan secara perorangan. Untuk melaksanakan perbaikan pembelajaran maka penulis sangat tertarik meneliti dalam mencari solusi untuk masalah belajar Aljabar yang dihadapi oleh siswa, penulis melaksanakan perbaikan pembelajaran, dengan memperbaiki teknik mengajar. Dimana penulis menemukan sebuah teknik belajar yang kemungkinan bisa menjadi solusi untuk masalah tersebut. Adapun teknik belajar yang ingin dicobakan dalam pembelajaran Aljabar siswa adalah teknik tutor sebaya. Penulis akan melihat apakah hasil belajar Aljabar siswa dapat meningkat apabila diajarkan dengan menggunakan teknik tutor sebaya.

Jurnal ini disusun berdasarkan catatan yang dibuat ketika merancang kegiatan perbaikan, serta selama pelaksanaan observasi dan diskusi pelaksanaan perbaikan pembelajaran yang dilakukan dalam 2 siklus PTK dalam mengajarkan Aljabar. Berkenaan dengan itu, jurnal ini memuat abstrak, pendahuluan, metode penelitian, serta hasil dan pembahasan.

\section{TINJAUAN PUSTAKA}

\section{Aljabar}

Aljabar adalah cabang matematika yang dapat dicirikan sebagai generalisasi dari bidang aritmatika. Aljabar berasal dari Bahasa Arab "al-jabr" yang berarti "pertemuan", "hubungan" atau"penyelesaian". Aljabar juga merupakan nama sebuah struktur aljabar abstrak, yaitu aljabar dalam sebuah bidang. Penemu aljabar adalah Abu Abdullah Muhammad Ibn Musa al-Khwarizmi. Dari pengertian di atas dapat ditarik kesimpulan bahwa aljabar merupakan suatu pembahasan yang memiliki kaitan erat dengan simbol dan relasi.

\section{Operasi pada Bentuk Aljabar (Aljabar SMP)}

Dalam mendiskusikan operasi pada bentuk-bentuk Aljabar, ada beberapa hal yang perlu untuk dipahami dengan baik, karena operasi-operasi dalam bentuk aljabar menjadi dasar yang penting dalam memahami bahasan-bahasan berikutnya. Operasioperasi pada bentuk aljabar mancakup operasi penjumlahan, pengurangan, perkalian dan 
pembagian dalam bentuk-bentuk aljabar termasuk bentuk-bentuk penyederhanaan dan aplikasinya (Karso, 2009).

\section{Penjumlahan dan Pengurangan Suku-suku serta Bentuk-bentuk Sejenis}

Tentunya kita telah mengenal bentuk-bentuk seperti $9 x-15 x$, dan $10 y-5-3 y+$ 6, dan sebagainya. Sekarang akan dipelajari bagaimana cara menyederhanakannya. Menyederhanakan suatu bentuk ialah mencari bentuk lain yang sama artinya dengan bentuk semula tetapi bentuknya lebih sederhana. Untuk menyederhanakan bentuk-bentuk itu digunakan sifat-sifat seperti:

a. sifat komutatif penjumlahan dan perkalian

$$
\begin{aligned}
& a+b=b+a \\
& a b=b a
\end{aligned}
$$

b. sifat asosiatif penjumlahan dan perkalian

$$
(a+b)+c=a+(b+c)
$$

$(a b) c=a(b c)$

c. sifat distributif perkalian terhadap penjumlahan $\mathrm{ab}+\mathrm{ac}=\mathrm{a}(\mathrm{b}+\mathrm{c}) ;$ a disebut faktor persekutuan.

\section{Menyatakan Perkalian Faktor-faktor sebagai Penjumlahan Suku-suku}

Seperti telah dipelajari bentuk yang mempunyai dua suku seperti $\mathrm{x}+2$ atau $\mathrm{x}+3$ disebut sukudua atau binom. Kita dapat menghitung hasil perkalian suku dua dengan memakai hukum distributif sebagai berikut:

$$
\begin{aligned}
& (\mathrm{x}+2)(\mathrm{x}+3) \\
& =\mathrm{x}(\mathrm{x}+3)+2(\mathrm{x}+3) \\
& =\mathrm{x} 2+3 \mathrm{x}+2 \mathrm{x}+6 \\
& =\mathrm{x} 2+5 \mathrm{x}+6
\end{aligned}
$$

Hasil itu dapat juga diperoleh dengan menggambar persegipanjang yang lebarnya $(x+2)$ satuan dan panjangnya $(x+3)$ satuan.

\section{Dua Pengkuadratan yang Penting}

Perkalian dua buah bentuk pengkuadratan berikut:

a. $(a+b)^{2}=(a+b)(a+b)$

$$
\begin{aligned}
& =a(a+b)+b(a+b) \\
& =a^{2}+a b+a b+b^{2}
\end{aligned}
$$

b. $(a-b)^{2}=(a-b)(a-b)$

$$
=a(a-b)-b(a-b)
$$$$
=a^{2}-a b-a b+b^{2}
$$

Perhatikanlah benar-benar

$$
\begin{aligned}
& (a+b)^{2}=(a+b)(a+b) \\
& (a-b)^{2}=(a-b)(a-b)
\end{aligned}
$$

Hasil pengkuadratan itu adalah:

Suku pertama adalah kuadrat suku pertama duasuku yang dikuadratkan, suku tengah adalah duakali hasil perkalian kedua suku. Suku ketiga adalah kuadrat suku kedua.

\section{Identitas atau Kesamaan (Equality)}

Kalimat $2 x=6$ merupakan kalimat terbuka. Kalimat itu menjadi benar jika " $\mathrm{x}$ " diganti dengan " 3 " dan salah jika diganti dengan lambing lain. Kalimat y2 $\times$ y $=y 3$ adalah kalimat yang benar untuk semua pengganti " $y$ " yang berupa bilangan nyata. Kalimat semacam itu disebut identitas. $(a+b)^{2}=a^{2}+2 a b+b^{2}$ dan $(a-b)^{2}=a^{2}-2 a b+b^{2}$ juga merupakan identitas. Untuk membuktikan bahwa suatu bentuk persamaan 
merupakan identitas, maka perlu ditunjukkan bahwa bentuk ruas kiri dapat dijadikan sama dengan bentuk ruas kanan.

\section{Tutor Sebaya}

\section{Pengertian Tutor}

Secara etimologi, tutor adalah guru pribadi, tenaga pengajar ekstra atau memberi les/pengajaran. Adapun yang dimaksud dengan pendidik adalah tenaga kependidikan yang berkualifikasi sebagai guru, dosen, konselor, pamong belajar, widyaiswara, tutor, instruktur, fasilitator dan sebutan lain yang sesuai dengan kekhususannya, serta berpartisipasi dalam menyelenggarakan pendidikan. Dimana tutor merupakan sebutan bagi orang yang mengajar dalam pendidikan non-formal, walaupun yang menjadi tutor adalah seorang guru dalam pendidikan formal. Metode tutorial merupakan cara penyampaian bahan pelajaran yang telah dikembangkan dalam bentuk modul untuk dipelajari siswa secara mandiri. Siswa dapat mengkonsultasikan tentang masalah-masalah dan kemajuan yang ditemui secara periodik (Nasution, 2003). Metode ini biasanya dilakukan pada SMP Terbuka, Paket A,B,C dan belajar jarak jauh dengan tatap muka terjadwal. Pendekatan tutorial merupakan pendekatan belajar sendiri oleh murid, menurut kecepatan masing-masing siswa untuk melaksanakan proses perkembangan pendidikan secara mandiri.

Tutor mengadakan evaluasi pada tiap-tap bagian modul yang memang telah diajarkan guna mengetahui apakah tujuan pengajaran telah dicapai atau belum. Apabila belum sesuai dengan apa yang diharapkan, maka seorang tutor harus mengulang materi sehingga sang murid dapat menguasai materi secara keseluruhan atau tidak pindah dari modul satu ke modul yang lain karena tujuan belum tercapai. Seorang guru di sini sebagai pengawas, mengawasi jalannya Pengajaran Terprogram, mereka membantu mengatur kelompok, menyesuaikan jadwal, membantu mengatasi kesulitan, menyempurnakan kompetensi yang belum dicapai secara sempurna dan mengelola keseluruhan administrasi pendidikan di sekolah tersebut (Muntasir, 1995).

Tugas seorang guru juga melatih para tutor untuk mengajar berdasarkan pedoman program silabus seperti pada butir (1). Hubungan antara tutor dengan anak-anak adalah hubungan antar kakak-adik atau antar kawan; kekakuan seperti yang ada pada guru agar dihilangkan. Bersama-sama para tutor yang lain dan guru, mereka menjadi semacam staf ahli yang mampu mengatasi kesulitan yang dihadapi murid, baik dengan cara satu lawan satu maupun kelompok kecil. Setiap tutor menghadapi empat sampai enam orang. Kelompok ini cukup kecil, sehingga metode mengajar yang ditetapkan berdasarkan teknik program itu memungkinkan setiap anak mendapatkan latihan dalam bentuk giliran lebih banyak. Mereka yang dengan cepat menguasai suatu item pengajaran tidak usah mendapat giliran lagi, sementara mereka yang tidak cepat menguasai akan mendapat giliran terus sampai dapat menguasai. Di sini waktu penguasaan disesuaikan dengan kondisi murid.

\section{Pengertian Tutor Sebaya}

Tutur sebaya adalah siswa di kelas tertentu yang memiliki kemampuan di atas rata-rata anggotanya yang memiliki tugas untuk membantu kesulitan anggota dalam memahami materi ajar (Tahusetya, 2007). Sedangkan menurut Dedi Supriyadi bahwa Tutor Sebaya adalah seorang atau beberapa orang peserta didik yang ditunjuk dan ditugaskan untuk membantu peserta didik yang mengalami kesulitan belajar. Tutor tersebut diambil dari kelompok yang prestasinya lebih tinggi (Novan, 2007).

Dan Menurut Ischak dan Warji, Tutor Sebaya adalah sekelompok peserta didik yang telah tuntas beban belajarnya, memberikan bantuan kepada peserta didik yang 
mengalami kesulitan dalam memahami bahan pelajaran yang dipelajarinya (Ischak dan Warji, 1987). Sedangkan Satriyaningsih mengatakan yang dimaksud dengan Tutor Sebaya adalah siswa yang ditunjuk atau ditugaskan membantu temannya yang mengalami kesulitan belajar, karena hubungan antar teman pada umumnya lebih dekat dibandingkan dengan hubungan antar guru dan siswa (Satriyaningsih, 2009).

Berdasarkan definisi-definisi dari Tutor Sebaya di atas, dapat diambil kesimpulan bahwa istilah Tutor Sebaya ialah sebuah strategi pembelajaran yang dilakukan dengan memanfaatkan siswa yang mempunyai keistimewaan, kepandaian dan kecakapan di dalam kelas untuk menjelaskan, membimbing, dan mengarahkan serta memberikan pandangan siswa yang kepandaiannya agak kurang atau lambat dalam menerima pelajaran yang usianya hampir sama atau sekelas.

Tutor sebaya terdiri dari Cross-Age Tutoring, Peer-Assisted Learning Strategies (PALS), dan Reciprocal Peer Tutoring (RPT). Ketiganya memiliki perbedaan pendekatan instruksional. Tetapi ketiga teori teori tersebut memiliki kesamaan yaitu: tutor sebaya memiliki pengaruh kuat pada motivasi dan prestasi akademik.

Diskusi kelompok terbimbing dengan model tutur sebaya merupakan kelompok diskusi yang beranggotakan 5-6 siswa pada setiap kelas di bawah bimbingan guru mata pelajaran dengan menggunakan tutor sebaya. Setiap tutor diberi sebuah modul pembelajaran. Kesulitan yang dialami oleh tutor dalam proses diskusi atau kemajuan (progress) dalam setiap pertemuan, di diskusikan dengan guru yang telah disepakati antara guru dan tutor (Desy, 2008).

\section{Prosedur Penyelenggaraan Tutor Sebaya}

Penerapan metode Tutor Sebaya pada kegiatan belajar mengajar dapat berjalan secara efektif serta efisien, apabila seorang guru memperhatikan serta melaksanakan beberapa langkah penyelenggaraan Tutor Sebaya. Adapun langkah-langkah tersebut adalah:

1) Menentukan yang akan dijadikan sebagai tutor

Dalam menentukan siapa yang akan dijadikan tutor diperlukan pertimbanganpertimbangan sendiri. Seorang tutor yang dipilih harus memiliki kriteria-kriteria sebagai berikut: (a) Memiliki kepandaian lebih unggul daripada siswa lain. (b) Memiliki kecakapan dalam menerima pelajaran yang disampaikan oleh guru.(c) Mempunyai kesadaran untuk membantu teman lain. (d) Mampu menjalin kerja sama dengan sesama siswa. (e) Memiliki motivasi tinggi untuk menjadikan kelompok tutornya sebagai yang terbaik. (f) Dapat diterima dan disenangi siswa yang mendapat program Tutor Sebaya, sehingga siswa tidak mempunyai rasa takut atau enggan untuk bertanya kepadanya dan rajin. (g) Tidak tinggi hati, kejam atau keras hati terhadap sesama kawan. (h) Mempunyai daya kreatifitas yang cukup untuk memberikan bimbingan yaitu dapat menerangkan pelajaran kepada kawannya.

2) Menyiapkan tutor

Menurut Suparno ada beberapa cara yang perlu diperhatikan dalam menyiapkan seorang tutor agar tutor dapat bekerja dengan optimal. Cara-cara tersebut yaitu: (a) Guru memberikan petunjuk pada tutor bagaimana mendekati temannya dalam hal memahami materi. (b) Guru menyampaikan pesan kepada tutor-tutor agar tidak selalu membimbing teman yang sama. (c) Guru membantu agar semua siswa dapat menjadi tutor sehingga mereka merasa dapat membantu teman belajar. (d) Tutor sebaiknya bekerja dalam kelompok kecil. Campuran siswa berbagai kemampuan (heterogen) akan lebih baik. (e) Guru memonitoring terus kapan tutor maupun siswa lain membutuhkan pertolongan. (f) Guru memonitoring Tutor Sebaya dengan berkunjung dan menanyakan kesulitan yang 
dihadapi setiap kelompok pada saat mereka diskusi di kelas maupun praktikum. (g) Tutor tidak mengetes temannya untuk grade, biarkan hal ini dilakukan guru (Suparno, 2007).

3) Membagi kelompok

Dalam metode Tutor Sebaya, seorang guru bertindak sebagai pengawas dan pengatur jalannya program ini. Sebelum memulai menerapkan metode Tutor Sebaya, seorang guru harus membagi peserta menjadi kelompok-kelompok kecil. Mengenai berapa banyaknya anggota setiap kelompok tidak ada ketentuan yang mutlak harus ditaati sebagai pedoman. Kelompok kecil sebaiknya dengan anggota 4-5 orang, dengan dasar pemikiran bahwa makin banyak anggota kelompoknya, keefektifan belajar tiap anggota berkurang. Sebaliknya jika terlalu sedikit 2 atau 3 orang, kurang dapat membentuk iklim kelompok yang baik.

Kelompok-kelompok dalam program Tutor Sebaya ini dapat dibentuk atas dasar minat dan latar belakang, pengalaman atau prestasi belajar. Kehangatan atau iklim kelompok yang baik dapat terbentuk berdasarkan adanya rasa persaudaraan antar anggota.

\section{Kelebihan dan Kekurangan Tutor Sebaya}

Menurut Suryo dan Amin, ada beberapa kelebihan metode Tutor Sebaya sebagaimana berikut: (a) Adanya suasana hubungan yang lebih dekat dan akrab antara siswa yang dibantu dengan siswa sebagai tutor yang membantu. (b) Bagi tutor sendiri, kegiatan remedial ini merupakan kesempatan untuk pengayaan dalam belajar dan juga dapat menambah motivasi belajar. (c) Bersifat efisien, artinya bisa lebih banyak yang dibantu. (d) Dapat meningkatkan rasa tanggung jawab dan kepercayaan diri (Suryo dan Amin, 1982).

Sedangkan kekurangan dari metode Tutor Sebaya yaitu: (a) Siswa yang dipilih sebagai tutor dan berprestasi baik belum tentu mempunyai hubungan baik dengan siswa yang dibantu. (b) Siswa yang dipilih sebagai tutor belum tentu bisa menyampaikan materi dengan baik.

Menurut Arikunto sebagaimana yang dikutip Sawali, ada beberapa kelebihan dan kekurangan metode Tutor Sebaya. Kelebihan-kelebihan tersebut yaitu: (a) Bagi beberapa siswa yang memiliki perasaan takut atau enggan kepada guru, metode ini akan menampakkan hasil yang lebih baik. (b) Bagi tutor sendiri, pekerjaan tutoring akan dapat memperkuat konsep yang sedang dibahas. (c) Membantu para tutor untuk melatih diri memeganng tanggung jawab dalam mengemban suatu tugas sekaligus sebagai wahana melatih kesabaran. (d) Mempererat hubungan antar siswa sehingga mempertebal perasaan sosial (Sawali, 2010).

Sedangkan kekurangan-kekurangan dari penerapan metode Tutor Sebaya yaitu: (a) Siswa yang dibantu seringkali kurang serius dalam belajar karena hanya berhadapan dengan temannya sendiri, sehingga hasilnya kurang memuaskan. (b) Ada sebagian siswa yang justru enggan ketika akan bertanya karena malu kelemahannya diketahui oleh temannya. (c) Pada kelas-kelas tertentu, pekerjaan tutoring sukar dilaksanakan karena adanya perbedaan jenis kelamin antara tutor dengan siswa yang ditutori. (d) Guru akan mengalami kesusahan dalam menentukan yang menjadi tutor karena tidak semua siswa yang pandai dapat mengajarkannya kembali pada teman-temannya. 2

\section{Penelitian Tindakan Kelas (Classroom Action Research)}

Classroom Action Research adalah Suatu Action research atau tindakan penelitian yang dilakukan di kelas. McNiff Classroom Action Research didefinisikan sebagai berikut.

Action research is a form of Self-Reflektif enquiry undertaken by perticapants (teachers, students or principal, for example) in social 
(including educational) situation in order to improve the rationality and justice of (a) their own social or educational practices, (b) their understanding of the practices, and the situation (and institution) in which the practices are carried out (McNiff, 1988).

Pengertian di atas mengandung beberapa ide pokok sebagai berikut:

a. Penelitina tindakan adalah suatu bentuk inkuiri atau penyelidikan yang dilakukan melalui refleksi diri.

b. Penelitian tindakan dilakukan oleh peserta yang terlibat dalam situasi yang diteliti, seperti guru, siswa atau kepala sekolah.

c. Penelitian tindakan dilakukan dalam situasi sosial, termasuk situasi pendidikan.

d. Tujuan penelitian tindakan adalah unutk mempernbaiki: dasar pemikirna dan kepantasan dari praktek-praktek, pemahaman terhadap praktek tersebut, serta situasi atau lambaga tempat praktek tersebut dilaksanakan.

Dapat disimpulkan bahwa penelitian tindakan kelas adalah penelitian yang dilakukan oleh guru di dalam kelasnya sendiri melalui refleksi diri, dengan tujuan untuk memperbaiki kinerjanya sebagai guru, sehingga hasil belajar siswa menjadi meningkat.

\section{Prosedur Penelitian Tindakan Kelas (Classroom Action Research)}

Prosedure dan metode dari penelitian tindakan kelas terdiri dari dua siklus. Dan tiap siklus akan didasarkan pada perencanaan sebelumnya. Tiap siklus akan direncanakan selama tiga bulan. Dan penelitian ini akan dilaksanakan berdasarkan metode penelitian tindakan kelas. Dalam pelaksanaan penelitian tindakan kelas ini, ada beberapa tahapan atau proses yang harus dilalui yaitu dimulai dari Pengidentifikasian masalah, analisis dan perumusan masalah, perencanaan perbaikan, melaksanakan tindakan, mengadakan observasi serta analisi dan refleksi. Untuk singkatnya dibawah ini disajikan prosedur penelitian tindakan kelas (Suharsimi, 2008).

\section{METODE}

Metode penelitian ini menggunakan Penelitian Tindakan Kelas (Classroom Action Research). Adapun lokasi yang digunakan dalam penelitian ini adalah SMP Negeri 175 yang berada di Jalan Raya Jati Padang Kebagusan Wates Jagakarsa Jakarta Selatan, dan adapun populasi yang digunakan dalam penelitian ini adalah seluruh kelas VIII berjumlah 240 orang. Adapun sampel dari penelitian ini adalah siswa kelas VIII.3 yang berjumlah 36 orang. Dalam pengumpulan data, penulis menggunakan test sebagi alat penelitian. Siswa dites dengan memberikan lembaran kerja siswa berupa ujian.

\section{HASIL DAN PEMBAHASAN}

\section{Data Penelitian}

Data dalam penelitian ini dikumpulkan dengan menggunakan tes untuk mata pelajaran Aljabar dengan terlebih dahulu dilakukan tes awal (Pre Test). Setelah diketahui hasil test awal, maka ditemukanlah bahwa siswa/i si kelas IV mengalami masalah dalam belajar Aljabar.

Tabel 1

Daftar Nilai Tes Awal (Pre Test) dalam belajar Aljabar

\begin{tabular}{clcc}
\hline \hline No & & Initial & NILAI \\
\hline 1 & LS & 4 \\
2 & TSS & 3 \\
3 & NS & 5
\end{tabular}




\begin{tabular}{|c|c|c|}
\hline 4 & RAHS & 6 \\
\hline 5 & GP & 6 \\
\hline 6 & TMN & 4 \\
\hline 7 & ELG & 5 \\
\hline 8 & DAS & 3 \\
\hline 9 & JS & 5 \\
\hline 10 & EG & 4 \\
\hline 11 & RPS & 6 \\
\hline 12 & DS & 5 \\
\hline 13 & CIS & 6 \\
\hline 14 & NS & 3 \\
\hline 15 & $\mathrm{RS}$ & 2 \\
\hline 16 & JST & 6 \\
\hline 17 & $\mathrm{RS}$ & 6 \\
\hline 18 & JSN & 3 \\
\hline 19 & DS & 2 \\
\hline 20 & ET & 3 \\
\hline 21 & EP & 3 \\
\hline 22 & $\mathrm{NN}$ & 4 \\
\hline 23 & NG & 3 \\
\hline 24 & KG & 3 \\
\hline 25 & HR & 3 \\
\hline 26 & DP & 4 \\
\hline 27 & SSS & 5 \\
\hline 28 & SOS & 3 \\
\hline 29 & SME & 6 \\
\hline 30 & SKD & 5 \\
\hline 31 & LD & 4 \\
\hline 32 & $\mathrm{LN}$ & 4 \\
\hline 33 & GUS & 3 \\
\hline 34 & GO & 4 \\
\hline 35 & FG & 4 \\
\hline 36 & $\mathrm{RD}$ & 4 \\
\hline \multicolumn{2}{|r|}{ TOTAL } & 149 \\
\hline
\end{tabular}

Maka jika dirata-ratakan, prestasi belajar siswa dalam belajar Aljabar adalah sebagai berikut:

Total Nilai Siswa

Rata kelas $=$

Jumlah Seluruh Siswa

Jadi Rata-Rata Kelas adalah Sebagai Berikut:

Rata-rata $=\frac{149}{36}$ Rata-rata $=4.1$

Maka dengan demikian perlu dilaksanakannya tindakan atau pengajaran siswa dengan menggunakan teknik belajar tutor sebaya untuk meningkatkan prestasi belajar siswa yang rendah. Dan diharapkan dengan dilaksanakannya pengajaran tersebut maka akan ada peningkatan terhadap prestasi belajar siswa.

Maka dilakasanakanlah siklus pertama pada penelitian peningkatan prestasi belajar siswa dan untuk itu dibawah ini dipaparkan bagaimana perubahan nilai atau 
peningkatan nilai dengan diterapkannya pembelajaran dengan menggunakan teknik belajar tutor sebaya.

\section{Siklus I}

Tabel II

Daftar Nilai Tes 1 (First Test) dalam belajar Aljabar

\begin{tabular}{|c|c|c|}
\hline No & INITIAL & NILAI \\
\hline 1 & LS & 6 \\
\hline 2 & TSS & 4 \\
\hline 3 & NS & 6 \\
\hline 4 & RAHS & 4 \\
\hline 5 & GP & 6 \\
\hline 6 & TMN & 3 \\
\hline 7 & ELG & 5 \\
\hline 8 & DAS & 3 \\
\hline 9 & JS & 5 \\
\hline 10 & $\mathrm{EG}$ & 7 \\
\hline 11 & RPS & 4 \\
\hline 12 & DS & 5 \\
\hline 13 & CIS & 3 \\
\hline 14 & NS & 7 \\
\hline 15 & $\mathrm{RS}$ & 4 \\
\hline 16 & JST & 6 \\
\hline 17 & $\mathrm{RS}$ & 5 \\
\hline 18 & JSN & 4 \\
\hline 19 & DS & 7 \\
\hline 20 & ET & 5 \\
\hline 21 & $\mathrm{EP}$ & 4 \\
\hline 22 & $\mathrm{NN}$ & 4 \\
\hline 23 & NG & 4 \\
\hline 24 & KG & 5 \\
\hline 25 & HR & 4 \\
\hline 26 & DP & 5 \\
\hline 27 & SSS & 5 \\
\hline 28 & SOS & 4 \\
\hline 29 & SME & 5 \\
\hline 30 & SKD & 5 \\
\hline 31 & $\mathrm{LD}$ & 6 \\
\hline 32 & $\mathrm{LN}$ & 4 \\
\hline 33 & GUS & 5 \\
\hline 34 & GO & 4 \\
\hline 35 & FG & 4 \\
\hline 36 & $\mathrm{RD}$ & 5 \\
\hline \multicolumn{2}{|r|}{ TOTAL } & 172 \\
\hline
\end{tabular}

Maka jika dirata-ratakan, prestasi belajar siswa dalam belajar Aljabar adalah sebagai berikut:

Total Nilai Siswa

Rata kelas $=$ 
Jumlah Seluruh Siswa

Jadi Rata-Rata Kelas adalah Sebagai Berikut:

Rata-rata $=\frac{172}{36}$

Rata-rata $=4.7$

Tabel III

Daftar Nilai Tes 2 (Post Test) dalam belajar Aljabar

\begin{tabular}{|c|c|c|}
\hline No & INITIAL & NILAI \\
\hline 1 & LS & 6 \\
\hline 2 & TSS & 5 \\
\hline 3 & NS & 7 \\
\hline 4 & RAHS & 6 \\
\hline 5 & GP & 6 \\
\hline 6 & $\mathrm{TMN}$ & 5 \\
\hline 7 & ELG & 5 \\
\hline 8 & DAS & 4 \\
\hline 9 & JS & 5 \\
\hline 10 & EG & 5 \\
\hline 11 & RPS & 6 \\
\hline 12 & DS & 5 \\
\hline 13 & CIS & 5 \\
\hline 14 & NS & 8 \\
\hline 15 & $\mathrm{RS}$ & 5 \\
\hline 16 & JST & 6 \\
\hline 17 & $\mathrm{RS}$ & 5 \\
\hline 18 & JSN & 6 \\
\hline 19 & DS & 6 \\
\hline 20 & ET & 6 \\
\hline 21 & $\mathrm{EP}$ & 5 \\
\hline 22 & NN & 6 \\
\hline 23 & NG & 5 \\
\hline 24 & KG & 5 \\
\hline 25 & HR & 7 \\
\hline 26 & DP & 7 \\
\hline 27 & SSS & 5 \\
\hline 28 & SOS & 5 \\
\hline 29 & SME & 6 \\
\hline 30 & SKD & 5 \\
\hline 31 & LD & 6 \\
\hline 32 & LN & 5 \\
\hline 33 & GUS & 5 \\
\hline 34 & GO & 6 \\
\hline 35 & FG & 7 \\
\hline 36 & $\mathrm{RD}$ & 5 \\
\hline \multicolumn{2}{|r|}{ TOTAL } & 202 \\
\hline
\end{tabular}

Maka jika dirata-ratakan, prestasi belajar siswa dalam belajar Aljabar adalah sebagai berikut: 
Total Nilai Siswa

Rata kelas =

Jumlah Seluruh Siswa

Jadi Rata-Rata Kelas adalah Sebagai Berikut:

Rata-rata $=\frac{202}{36}$

Rata-rata $=5.6$

Dengan diadakannya pembelajaran dengan menggunakan teknik belajar tutor sebaya dalam membantu peningkatan prestasi siswa dalam belajar Aljabar maka, dari data yang sudah ditampilakan pada tabel $1-3$ di siklus peratama di atas, maka dapat kita lihat dengan jelas bahwa adanya peningkatan prestasi belajar siswa. Walaupun tidak begitu tinggi. Seperti yahng sudah kita lihat di atas, peningkatan presatasi belajar siswa dari ujian pre-test yang diadakan sebelum dilaksanakannya pengajaran remedial adalah berkisar;

Rata-rata kelas dalam pre-test (test awal) $=4.1$

Rata-rata kelas dalam first test (Siklus 1$)=4.7$

Maka adapun besar peningkatan dari prestasi belajar siswa adalah sebagai berikut:

Nilai first test - Nilai test awal (pre test)

Peningkatan $=4.7-4.1$

$$
\begin{aligned}
& =0.6 \\
& =14.6 \%
\end{aligned}
$$

Jadi besar peningkatan yang diperoleh dari hasil pengajaran remedial untuk mata pelajaran exacta yaitu sebesar $14.6 \%$

Jadi setelah pelaksanaan pembelajaran dengan teknik tutor sebaya dan pelaksanaan first-test, maka ditemukanlah bahwa adanya peningkatan. Tetapi peningkatan tersebut tidak terlalu tinggi sehingga perlu dilaksanakan kembali pembelajaran Aljabar dengan teknik tutor sebaya hingga akhir siklus. Di akhir siklus pertama, maka akan diadakan Post test (test akhir). Dan adapun peningkatan yang didapat dari pelaksanaan test 2 (Post-test) dalam pembelajaran Aljabar adalah sebagai berikut:

Rata-rata kelas dalam test awal (Fist-test) dalam belajar Aljabar $=4.7$

Rata-rata kelas dalam Test 2 (Post-test) dalam belajar Aljabar $=5.6$

Maka adapun besar peningkatan dari prestasi belajar siswa adalah sebagai berikut:

Nilai Test 2 (Post Test) - Nilai first-test

Peningkatan $=5.6-4.7$

$=0.9$

$=19.1 \%$

Jadi besar peningkatan yang diperoleh dari hasil pengajaran Aljabar dengan menggunakan teknik belajar turtor sebaya adalah $19.1 \%$.

Total peningkatan hasil belajar Aljabar siswa dengan menggunakan metode tutor sebaya adalah sebagai berikut:

Rata-rata nilai Post-Test - Rata-rata Nilai Pre-Test

Maka adapun besar peningkatan dari prestasi belajar siswa adalah sebagai berikut:

Peningkatan $=5.6-4.1$

$$
=1.5
$$$$
=36.58 \%
$$

Jadi besar peningkatan yang diperoleh dari hasil pengajaran Aljabar dengan menggunakan teknik belajar turtor sebaya pada siklus pertama adalah yaitu sebesar $36.58 \%$. 
Melihat peningkatan yang tidak begitu signifikan maka, penelitian ini dilanjutkan ke siklus yang ke dua untuk mendapatkan peningkatan yang lebih significan lagi. Adapun hasil peningkatan yang dapat diperoleh dalam siklus yang ke dua adalah sebagai berikut:

\section{Siklus II}

Tabel IV

Daftar Nilai Tes 1 Siswa dalam Belajar Aljabar pada Siklus II

\begin{tabular}{|c|c|c|}
\hline No & INITIAL & NILAI \\
\hline 1 & $\mathrm{LS}$ & 7 \\
\hline 2 & TSS & 8 \\
\hline 3 & NS & 7 \\
\hline 4 & RAHS & 7 \\
\hline 5 & GP & 6 \\
\hline 6 & TMN & 7 \\
\hline 7 & ELG & 7 \\
\hline 8 & DAS & 6 \\
\hline 9 & JS & 8 \\
\hline 10 & $\mathrm{EG}$ & 8 \\
\hline 11 & RPS & 8 \\
\hline 12 & DS & 6 \\
\hline 13 & CIS & 7 \\
\hline 14 & NS & 7 \\
\hline 15 & $\mathrm{RS}$ & 6 \\
\hline 16 & JST & 6 \\
\hline 17 & $\mathrm{RS}$ & 7 \\
\hline 18 & JSN & 7 \\
\hline 19 & DS & 7 \\
\hline 20 & ET & 7 \\
\hline 21 & EP & 7 \\
\hline 22 & $\mathrm{NN}$ & 6 \\
\hline 23 & NG & 6 \\
\hline 24 & KG & 7 \\
\hline 25 & HR & 7 \\
\hline 26 & DP & 6 \\
\hline 27 & SSS & 6 \\
\hline 28 & SOS & 5 \\
\hline 29 & SME & 6 \\
\hline 30 & SKD & 5 \\
\hline 31 & LD & 7 \\
\hline 32 & $\mathrm{LN}$ & 6 \\
\hline 33 & GUS & 6 \\
\hline 34 & GO & 6 \\
\hline 35 & FG & 7 \\
\hline 36 & $\mathrm{RD}$ & 6 \\
\hline \multicolumn{2}{|r|}{ TOTAL } & 238 \\
\hline
\end{tabular}

Jadi setelah pelaksanaan pengajaran Aljabar dengan teknik tutor sebaya pada siklus yang ke dua, maka test pertama diadakan dan hasilnya ditemukanlah bahwa adanya peningkatan. Tetapi peningkatan tersebut tidak terlalu tinggi sehingga perlu dilaksanakan 
kembali pengajaran remedaial hingga akhir siklus. Dan adapun peningkatan yang didapat dari pelaksanaan test pertama adalah sebagai berikut:

Total Nilai Siswa

Rata kelas $=$

Jumlah Seluruh Siswa

Jadi Rata-Rata Kelas adalah Sebagai Berikut:

Rata-rata $=\frac{238}{36}$

Rata-rata $=6.6$

Tabel V

Daftar Nilai Tes 2 (Post-Test) Siswa dalam Belajar Aljabar pada Siklus II

\begin{tabular}{|c|c|c|}
\hline No & NAMA & NILAI \\
\hline 1 & LS & 7 \\
\hline 2 & TSS & 9 \\
\hline 3 & NS & 7 \\
\hline 4 & RAHS & 7 \\
\hline 5 & GP & 7 \\
\hline 6 & TMN & 7 \\
\hline 7 & ELG & 7 \\
\hline 8 & DAS & 7 \\
\hline 9 & JS & 8 \\
\hline 10 & EG & 9 \\
\hline 11 & RPS & 8 \\
\hline 12 & DS & 7 \\
\hline 13 & CIS & 7 \\
\hline 14 & NS & 7 \\
\hline 15 & RS & 7 \\
\hline 16 & JST & 7 \\
\hline 17 & $\mathrm{RS}$ & 8 \\
\hline 18 & JSN & 7 \\
\hline 19 & DS & 7 \\
\hline 20 & ET & 7 \\
\hline 21 & EP & 7 \\
\hline 22 & NN & 7 \\
\hline 23 & NG & 8 \\
\hline 24 & KG & 7 \\
\hline 25 & HR & 8 \\
\hline 26 & DP & 7 \\
\hline 27 & SSS & 7 \\
\hline 28 & SOS & 6 \\
\hline 29 & SME & 7 \\
\hline 30 & SKD & 7 \\
\hline 31 & LD & 7 \\
\hline 32 & LN & 7 \\
\hline 33 & GUS & 7 \\
\hline 34 & GO & 8 \\
\hline 35 & FG & 7 \\
\hline 36 & RD & 7 \\
\hline \multicolumn{2}{|r|}{ TOTAL } & 261 \\
\hline
\end{tabular}


Maka jika dirata-ratakan, prestasi belajar siswa untuk mata pelajaran Exacta adalah sebagai berikut:

$$
\text { Rata kelas }=\frac{\text { Total Nilai Siswa }}{\text { Jumlah Seluruh Siswa }}
$$

Jadi Rata-Rata Kelas adalah Sebagai Berikut:

Rata-rata $=\frac{261}{36}$

Rata-rata $=7.2$

Rata-rata kelas dalam belajar Aljabar pada Test 1 siklus II $=6.6$

Rata-rata kelas dalam belajar Aljabar pada Test 2 (Post-Test) siklus II $=7.2$ berikut:

Maka adapun besar peningkatan dari prestasi belajar siswa adalah sebagai

Nilai Rata-Rata test Akhir 2 (Post-Test) - Nilai rata-rata test 1 siklus II

Peningkatan $=7.2-6.6$

$$
\begin{aligned}
& =0.6 \\
& =9.09 \%
\end{aligned}
$$

Jadi besar peningkatan yang diperoleh dari hasil pengajaran remedial untuk mata pelajaran exacta yaitu sebesar $9.09 \%$

Total peningkatan hasil belajar Aljabar siswa dengan menggunkan teknik belajar tutor sebaya dari Pre-Test hingga dengan Siklus ke dua adalah sebagai berikut:

Nilai Rata-Rata Post-test Siklus II - Nilai Rata-Rata Pre-Test

$$
\begin{aligned}
\text { Peningkatan } & =7.2-4.1 \\
& =3.1 \\
& =75.6 \%
\end{aligned}
$$

Maka dari hasil tersebut, dapat diketahui bahwa pengajaran Aljabar dengan menggunakan teknik belajar tutor sebaya betul-betul dapat membantu siswa dalam mengatasi masalah prestasi belajar Aljabar yanng rendah. Dan dari hasil tersebut yang sudah mencapai tingkat kemaksimalan yaitu nilai siswa berkisar $75.6 \%$ atau jumlah nilai rata-rata kelas $=70$. Maka peneliti tidak usah lagi melanjutkan penelitiannya ke siklus berikutnya., karena hasil yang ingin dicapai sudah diperoleh pada akhir siklus ke dua, dimana nilai rata-rata siswa sudah memenuhi standar nilai kelulusan.

\section{PENUTUP}

Berdasarkan hasil penelitian dan pembahasan, dapat ditarik kesimpulan sebagai berikut: (a) Pengajaran dengan menggunakan teknik tutor sebaya dikategorikan sangat baik dalam peningkatan prestasi belajar siswa dalam bidang belajar Aljabar, ini dapat dilihat dari peningkatan nilai rata-rata siswa dalam setiap test. (b) Prestasi belajar siswa dalam bidang Aljabar dikategorikan sangat bagus, ini dapat dilihat dari capaian nilai ratarata prestasi belajar peserta sebesar 8.35. (c) Pengajaran dengan menggunakan teknik belajar tutor sebaya dalam dalam belajar Aljabar mencapai target yang diinginkan pada siklus yang dua.

Dari kesimpulan yang telah disebutkan di atas dapat diambil saran bahwa Pengajarn dengan menggunakan teknik tutor sebaya sangat bagus apabila diterapkan dengan benar dalam meningkatkan pengetahuan siswa dalam bidang Aljabar dan juga sangat disarankan untuk melakukan penelitian yang lebih lanjut dalam bidang pengajaran matematika yang lain. 


\section{DAFTAR PUSTAKA}

Antonius Novan S. N. 2007. Model Pembelajaran Tutor Sebaya dengan Memanfaatkan LKS dan Alat Peraga Papan Berpaku Sebagai Upaya Meningkatkan Hasil Belajar dan Aktivitas Belajar Matematika Pada Pokok Bahasan Simetri Lipat dan Pencerminan Bagi Peserta Didik Kelas V SD Rejosari 03 Semarang. Skripsi, Fakultas Matematika dan Ilmu Pengetahuan Alam Universitas Negeri Semarang.

Desy, P. R. dkk. 2008. Pengaruh Model Pembelajaran Tutor Sebaya Tipe Peer Assisted Learning Strategies pada Komunitas Belajar On Line terhadap Hasil Belajar Teknologi Informasi dan Komunikasi. FPMIPA UPI.

Ischak dan Warji. 1987. Program Remidial dalam Proses Belajar Mengajar.

Karso, H. 2009. Bentuk-Bentuk Aljabar_Pembelajaran Matematika SMP. FPMIPA UPI

Krismanto, Al. 2003. Aljabar di SMP. Naskah Bahan Diklat pada Diklat Matematika untuk Guru SLTP, Juli, 2003. di PPPG Matematika. PPPG Matematika: Yogyakarta.

McNiff, J. 1988. Action Research: Principles and Practice. Basingstoke: Macmillan.

Moh Suryo dan Moh. Amin. 1982. Pengajaran Remedial. Jakarta: Depdikbud P2BSPG.

P. Suparno. 2007. Metodologi Pembelajaran Fisika; Konstruktivistik dan Menyenangkan. Yogyakarta: Universitas Santa Dharma.

Saleh Muntasir. 1995. Pengajaran Terprogram. Jakarta: CV. Rajawali.

S. Nasution. 2003. Berbagai Pendekatan dalam Proses Belajar Mengajar. Jakarta: Bumi Aksara.

Satriyaningsih. 2009. Efektivitas Metode Pembelajaran Tutor Sebaya untuk Meningkatkan Hasil Belajar Biologi pada Pokok Bahasan Ekosistem pada Siswa Kelas VII SMP Bhinneka Karya Klego Boyolali Tahun Ajaran 2008/ 2009. Skripsi, Fakultas Keguruan dan Ilmu Pendidikan Universitas Muhammadiyah Surakarta.

Sawali. Diskusi Kelompok Terbimbing Metode Tutor Sebaya (http://sawali.info/ diakses 21 Maret 2010)

Suharsimi Arikunto. 2008. Penelitian Tindakan Kelas. Jakarta: Bumi Aksara.

Tuhusetya, S. 2007. Diskusi Kelompok Terbimbing Model Tutor Sebaya.[online]. Tersedia: http://sawali.info/2007/12/29/diskusi-kelompok-terbimbing-modeltutor-sebaya/

Undang-undang RI Nomor 20 Tahun 2005 Tentang Guru dan Dosen \& Undangundang RI Nomor 20 Tahun 2003 Tentang Sistem Pendidikan Nasional. 